\title{
VALORAÇÃO AMBIENTAL DO PARQUE MUNICIPAL LAGOA ENCANTADA, CUIABÁ (MT)
}

\author{
Suelen da Veiga Borges Leão* \\ Roberto Antonio Ticle de Sousa* \\ Maria Corette Pasa
}

RESUMO: Este trabalho tem como objetivo expressar o valor de uso recreacional do Parque Municipal Lagoa Encantada (PMLE), utilizando-se os métodos de Valoração Contingente e o método do Custo de Viagem. O estudo foi desenvolvido no perímetro urbano de Cuiabá, com os dados coletados através de questionários em entrevistas feitas aleatoriamente junto aos usuários do Parque. Aplicou-se 110 questionários. Os valores obtidos pelo Método Custo de Viagem mostram que os frequentadores entrevistados no parque têm uma disposição para desembolsar o equivalente a $R$ \$ 1,03/pessoa/visita ao parque. A disposição média a pagar encontrada para o público entrevistado pelo Método de Valoração Contingente foi de um valor que se situa entre $R \$ 0,50 \mathrm{e} R \$ 1,00$ por pessoa/visita ao parque. O parque atende todas as faixas etárias, característica que demonstra acerto na estrutura e funcionamento no atendimento ao público de ambos os sexos. A maioria dos usuários $(80,9 \%)$ reside nas imediações do parque, demonstrando que a proximidade do parque é forte atrativo para visitação principalmente para atividades físicas como a caminhada. Entre os 110 entrevistados, existe uma maior proporção de visitantes do sexo feminino, 61,8\%, e $38,2 \%$ dos frequentadores do sexo masculino. Pelo Método de Custo de Viagem o va-

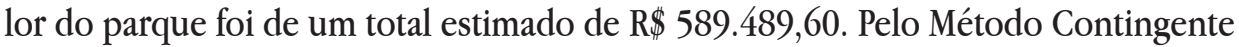
a disposição média a pagar foi de $R \$ 1,00$ um total estimado de $R$ \$ 572.320,00 como o valor do parque pelo Método de Valoração Contingente na melhor das hipóteses.

PALAVRAS-CHAVE: Custo de viagem; Valor ambiental; Valoração contingente.

\footnotetext{
Mestre em Ciências Ambientais e Florestais no Departamento de Engenharia Florestal, Área Meio Ambiente da Universidade Federal de Mato Grosso (UFMT), Brasil. E-mail: suelenleao.tangara@gmail.com

** Doutor em Economia Aplicada, Docente permanente da FENF- UFMT, atuando na graduação e pós-graduação, nas áreas de recursos florestais e ambientais, com ênfase em economia, administração e transporte florestal da Universidade Federal de Mato Grosso (UFMT), Brasil.

*** Pós-Doutorado em Etnobotânica e Etnofarmacobotânica na Cultura de Comunidades Afrodescendentes. Professora da Classe Associado do Departamento de Botânica e Ecologia - Instituto de Biociências (UFMT), Cuiabá, Brasil.
} 


\title{
ENVIRONMENTAL VALORIZATION OF THE MUNICIPAL PARK LAGOA ENCANTADA, CUIABÁ, BRAZIL
}

\begin{abstract}
The recreational value of Municipal Park Lagoa Encantada is given by the Contingent Valorization and Travel Costs methods. Current study was developed within the urban perimeter of Cuiabá MT Brazil, and used data from 110 questionnaires in randomized interviews by people in the MPLE. Rates by Travel Costs Method revealed that interviewed park users were willing to pay $\mathrm{R} \$ 1.03 /$ person/ visit to the park. Employing the Contingent Valorization Method, mean payment suggested by people lay between $R \$ 0.50$ and $R \$ 1.00$ per person/visit to the park. Since the park attends the needs of people in all age brackets, its structure and function for the general public proved to be correct. Most users (80.9\%) live in the neighborhood. This fact shows that closeness of the park is highly attractive for visitation, especially for the practice of physical exercises, such as walking. Out of the 110 interviews, females $(61.8 \%)$ are the most frequent users, followed by males (38.2\%). Assets of the park amounted to $\mathbf{R} \$ 589,489.60$ by the Travel Costs Method, whilst total was estimated by the Contingent Valorization Method at $\mathrm{R} \$ \mathbf{5 7 2 , 3 2 0 . 0 0}$ at $\mathrm{R} \$ 1.00$ per visitor, at the best.
\end{abstract}

KEY WORDS: Travel costs; Environmental value; Contingent valorization.

\section{INTRODUÇÃO}

A situação do meio ambiente no globo terrestre nos desafia a preservar os recursos naturais e possibilitar um desenvolvimento social, permitindo que a sociedade humana atinja uma melhor qualidade de vida em todos os aspectos. A necessidade de consolidar novos modelos de desenvolvimento sustentável no país exige a construção de alternativas de utilização dos recursos, orientada por uma racionalidade ambiental e uma ética da solidariedade.

O problema ambiental do planeta surge devido aos recursos serem esgotáveis e que não pode absorver todo o impacto ambiental gerado pela espécie humana, nos padrões atuais. Simultaneamente, a sociedade se estruturou sob um modelo econômico que depende do desenvolvimento contínuo para gerar recursos e propiciar condições mínimas de sobrevivência para uma volumosa população, dando o 
tom dramático à relação complexa entre necessidades econômicas e preservação da vida (SALLES, 2010).

Segundo os dados do Cadastro Nacional de Unidades de Conservação (CNUC), mantido e gerenciado pelo Ministério do Meio Ambiente (MMA), as UCs criadas e administradas pelos governo federal e governos estaduais somam 698 unidades, enquanto as Reservas Particulares do Patrimônio Natural (RPPNs) outras 973. Juntas, essas unidades estão distribuídas por todos os biomas do Brasil e recobrem aproximadamente 15\% do território nacional (MEDEIROS et al., 2011). Dentre essas Unidades de Conservação federais, segundo o grupo e as categorias de manejo com PROTEÇÃO INTEGRAL, estão distribuídos em Parque Nacional 48,9\%, Reserva Biológica 21,2\%, Estação Ecológica 22,6\%, Monumento natural 2,2\% e Refúgio da vida silvestre $5,1 \%$.

A maior parte dos problemas enfrentados pelo SNUC tem a mesma causa em comum: recursos insuficientes para sua implementação e manutenção, incluindo a criação de novas áreas.

Segundo Cunha e Menezes (2005), as Unidades de Conservação apresentam maior vulnerabilidade em relação às áreas protegidas mais remotas, principalmente em relação aos impactos decorrentes do processo de urbanização, as dimensões reduzidas das áreas verdes, pressão humana, introdução de espécies exóticas, contaminação dos mananciais e entre outros fatores, e se tratando de políticas públicas de conservação da natureza raramente esses fatores têm prioridade nas discussões para minimizar os impactos ambientais.

Devido ao possível esgotamento dos recursos naturais, surgiram vários estudos buscando o manejo e a conservação do meio ambiente, utilizando, para isso, diversas metodologias que visam levantar o valor intrínseco dos bens e serviços ambientais, expressos por meio dos processos de valorização econômica (TOGNELLA, 1995).

A valoração dos bens ambientais visa garantir recursos naturais para gerações futuras, dentro dos preceitos do desenvolvimento sustentável. E do ponto de vista econômico, para que haja desenvolvimento sustentável, é preciso que; o crescimento seja definido de acordo com a capacidade de suporte dos recursos naturais, nestas condições é necessário valorar economicamente o meio ambiente (FERREIRA, 2003). 
Segundo Mota (1997) o valor econômico dos recursos ambientais geralmente não é observável no mercado através de preços que reflitam seu custo de oportunidade.

De acordo com Nogueira e Medeiros (1998), de uma maneira geral, os métodos de valoração econômica ambiental são utilizados para estimar os valores que as pessoas atribuem aos recursos ambientais, com base em suas preferências individuais e podem estar ou não associados a um uso.

Embora o uso de recursos ambientais não tenha seu preço reconhecido no mercado, seu valor econômico existe na medida que seu uso altera o nível de produção e consumo (bem-estar) da sociedade, por isso, estes custos e benefícios são expressos em termos monetários e essa análise de custo-benefício é apenas um indicador adicional para a tomada de decisão.

Considerando os benefícios socioambientais que representam, os estudos de valoração econômica com vistas a quantificá-los são de extrema importância para subsidiar o processo de gestão das políticas públicas ambientais.

Este trabalho tem como objetivo estimar os valores de uso recreacional do Parque Municipal Lagoa Encantada, utilizando-se os métodos de Valoração Contingente e do Custo de Viagem e, através destes, analisar o perfil socioeconômico dos frequentadores.

\section{MATERIAL E MÉTODOS}

Neste trabalho, optou-se por empregar o Método de Custo de Viagem (MCV) e o Método Valoração Contingente (MVC) para estimar o valor do uso recreacional do Parque Municipal Lagoa Encantada.

\section{1 ÁREA DE ESTUDO}

O Parque Municipal Lagoa Encantada está localizado no perímetro urbano do município de Cuiabá, Mato Grosso, entre as coordenadas geográficas $15^{\circ} 33$ '57,11'S e 56 $02^{\prime} 29,57^{\prime \prime} \mathrm{W}$, com 30,9 hectares de área total, tendo como limi- 
tes a Rua Tancredo Neves e a Alameda 6, no bairro Morada da Serra. A Estação de Tratamento de Esgoto - ETE, da Companhia de Saneamento da Capital (Sanecap), no CPA III, em Cuiabá, abriga hoje o complexo da Lagoa Encantada, criado com o objetivo de realizar atividades ligadas ao meio ambiente e cidadania, além de promover a conscientização da preservação ambiental. A iniciativa do empreendimento reestruturado na gestão do ex-prefeito Wilson Santos foi inaugurada em 30/09/2009.

O Parque apresenta uma estrutura ecologicamente correta, esta é a primeira ETE do Brasil com lagoas de decantação, além de se transformar em um espaço multiuso, as três lagoas que antes eram apenas locais de captação de esgoto, hoje têm capacidade para tratar dejetos que serão lançados de forma ambientalmente correta no Córrego Caju e posteriormente no Rio Cuiabá e também utilizada nas suas intermediações para atividade sociais, como esporte e lazer, compreendendo em 30,9 ha com pista de caminhada de 1,9km, aparelhos de ginástica, mirante, quiosque, maquete de bacia hidrográfica e viveiro, todos voltados para a educação socioambiental.

Este projeto contempla ações de capacitação e mobilização em recursos naturais, em específico; os recursos hídricos e Tecnologia para Otimização do Uso da Água em Domicílios, por meio do Sistema de Reuso de Água para a Alimentação de Descargas Domésticas, aprovado pelo MCT/CT-HIDRO/CNPq (Conselho Nacional de Desenvolvimento Científico e Tecnológico) no valor de $\mathrm{R} \$ 190.785,00$, que prevê atividades de Reuso da Água de Enxágüe de máquinas de lavar roupa.

A pista de caminhada e a praça de ginástica, por exemplo, são disputadas por jovens, adultos e idosos que encontram ali um lugar adequado para se exercitarem. Já o auditório é usado para reuniões, palestras e cursos, inclusive para aulas do curso de mestrado de engenharia sanitária da Universidade Federal de Mato Grosso (UFMT) e a maquete é uma opção educativa para os alunos, que podem visitá-la diariamente para conhecer um pouco da história da bacia hidrográfica de Cuiabá (Figura 1). 

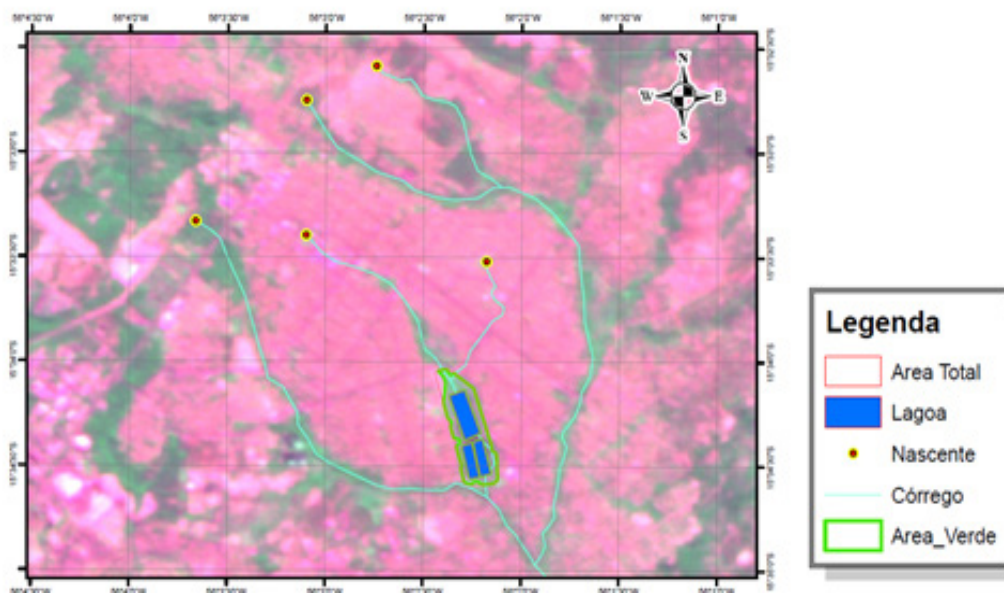

Figura 1. Vista aérea do Parque Municipal Lagoa Encantada, Cuiabá (MT).

\subsection{COLETA DE DADOS}

Para levantamento dos dados deste trabalho, utilizou-se da aplicação aleatória de questionários individualmente a cada visitante nos portões do Parque Lagoa Encantada, sob a forma de entrevista.

A entrevista estruturada é uma técnica de produção de dados, que se baseia na utilização de um questionário como instrumento de coleta de dados. Ela baseia-se em uma estrutura uniforme, enquanto um número calculado de pessoas é entrevistado de modo que seja considerada uma amostra estaticamente representativa da população para propósitos de generalização (MAY, 2004).

$\mathrm{O}$ procedimento empregado na pesquisa de campo, tanto para aplicação do método de valor contingente como para o método do custo de viagem, constou de aplicação de questionários sob forma de entrevista. Os questionários utilizados são classificados como fechados, em que se pede para o entrevistado escolher uma alternativa em uma lista apresentada.

O questionário utilizado buscou levantar informações do entrevistado quanto ao gênero, grau de escolaridade, atividade profissional, renda familiar mensal e bairro/local de residência do visitante, os objetivos ou motivos da visita ao parque; suas atividades recreativas preferidas; número de visitações por semana; tempo de 
permanência no parque; o tempo de deslocamento da residência até ao parque; distância percorrida da residência até ao parque; período do dia de maior preferência; segurança (se os visitantes se sentem seguros ou não nas imediações da Lagoa); disposição a pagar em termos de valores, por cada visita ao parque e se já souberam de ocorrência de assalto no interior do parque.

Foi aplicado um total de 110 questionários aleatoriamente, de segunda a domingo, nos turnos matutino e vespertino, no período de 16/11/2010 a 23/11/2010, com a finalidade de levantar o perfil dos entrevistados, suas características socioeconômicas, informações para aplicação do método de valoração de custo de viagem e do método de valoração contingente.

\subsection{MÉTODO DE CUSTO DE VIAGEM (MCV)}

Para usar os serviços recreativos do parque, os indivíduos têm de se deslocar dos diferentes pontos de origem da cidade até esse local de recreação. Os custos envolvidos nesse deslocamento são parte significativa do preço pago pelo indivíduo para visitar o local. Através do questionário, procura-se identificar os gastos feitos pelos entrevistados para se deslocar até o parque, identificando os diferentes meios de locomoção.

O custo de transporte foi obtido através das respostas dos entrevistados quanto ao meio de transporte utilizado. Para os entrevistados que responderam ir a pé ou de bicicleta considerou-se custo zero. Para os visitantes que utilizaram o transporte de ônibus (GP), foram consideradas as tarifas vigentes na cidade de Cuiabá em novembro de 2010, no valor de $\mathrm{R} \$ 2,50$. Para os que tinham carro ou moto como meio de transporte foi adotada a seguinte fórmula proposta por Abreu (2008), conforme equação abaixo.

$$
G C=\frac{D P}{C M}(P C)
$$

Onde: $G C=$ Gastos com Combustível; $D P=$ Distância Percorrida; $C M=$ Consumo Médio por Litro de Combustível; $P C=$ Preço do Combustível por litro. 
O gasto foi calculado considerando o preço da gasolina e do álcool no mês de novembro de 2010, época da aplicação dos questionários, que era $\mathrm{R} \$ 2,87$ /itro para o litro de gasolina e $\mathrm{R} \$ 1,57$ /litro de álcool. Para cálculo do custo de translado considerou-se um carro popular o qual tem um consumo médio de $13 \mathrm{~km} /$ litro e uma moto $30 \mathrm{~km} /$ litro.

\subsection{O MÉTODO DE VALORAÇÃO CONTINGENTE (MVC)}

O questionário para levantamento da DAP no MVC submete o entrevistado a opções dentro de uma lista de diferentes intervalos de valores de taxa de admissão ao parque (valor da entrada).

O MVC consiste em uma metodologia de coleta, elaboração e análise de dados, é baseado nas preferências dos consumidores através de questionários quantitativos, que procuram captar as disposições a pagar (DAP) pelo uso ou preservação de um bem ambiental.

Para a efetivação do cálculo da Disposição a Pagar (DAP), trabalhou-se com a fórmula sugerida por Motta adaptada por Finco (2011), conforme equação abaixo:

$$
\mathrm{DAP}=\left[\sum \mathrm{dap} /(\mathrm{ni} / \mathrm{N}) \cdot 100\right] . \mathrm{M}
$$

Onde,

DAP $=$ Total da disposição a pagar

$\sum=$ Somatório

$\sum$ dap $=$ disposição a pagar por indivíduo

$\mathrm{ni}=$ Número de entrevistados dispostos a pagar

$\mathrm{N}=$ Número total de pessoas entrevistadas

$\mathrm{M}=$ Número de visitantes estimados na área recreacional durante o período de estudo.

Para o alcance do valor de disposição a pagar, trabalhou-se com o intervalo entre os valores $R \$ 0,50$ e máximo de $\mathrm{R} \$ 20,00$, em moeda corrente brasileira (real). 


\section{RESULTADO E DISCUSSÃO}

O Parque Municipal Lagoa Encantada (PMLE) funciona das 05h30min às 18h sem interrupção, não sendo cobrada taxa de visitação. Através dos dados amostrais de frequência do parque, estimou-se que o número de visitantes é cerca de 1.568 visitantes por dia, no período em que os questionários foram aplicados.

\subsection{PERFIL SOCIOECONÔMICO DOS ENTREVISTADOS}

A maioria dos usuários $(80,9 \%)$ reside nas imediações do parque, demonstrando que a proximidade do parque é forte atrativo para visitação principalmente para atividades físicas como a caminhada. Esse resultado é semelhante ao encontrado em outros trabalhos, como no levantamento realizado no Parque da Cidade Mãe Bonifácia, na cidade de Cuiabá (MT), onde 59\% dos visitantes eram moradores de bairros circunvizinhos, devido à preferência pela proximidade de suas residências (VILLANOVA, 2008). Outro resultado semelhante é encontrado no Parque Ingá, na cidade de Maringá (PR), com 52\% dos frequentadores residindo nas proximidades do parque (TAKAHASHI; MARTINS, 1990).

No que diz respeito à distância percorrida pelos usuários desde suas residências até ao parque, $71,11 \%$ estão na faixa de 0 a 1 quilômetro, $16,67 \%$ percorrem até 4 quilômetros, e 3,33\% percorrem até 6 quilômetros de distância. Quanto ao tempo de deslocamento da residência até ao Parque, $40 \%$ dos frequentadores demoram 10 minutos no trajeto de ida e volta (Figura 2). 


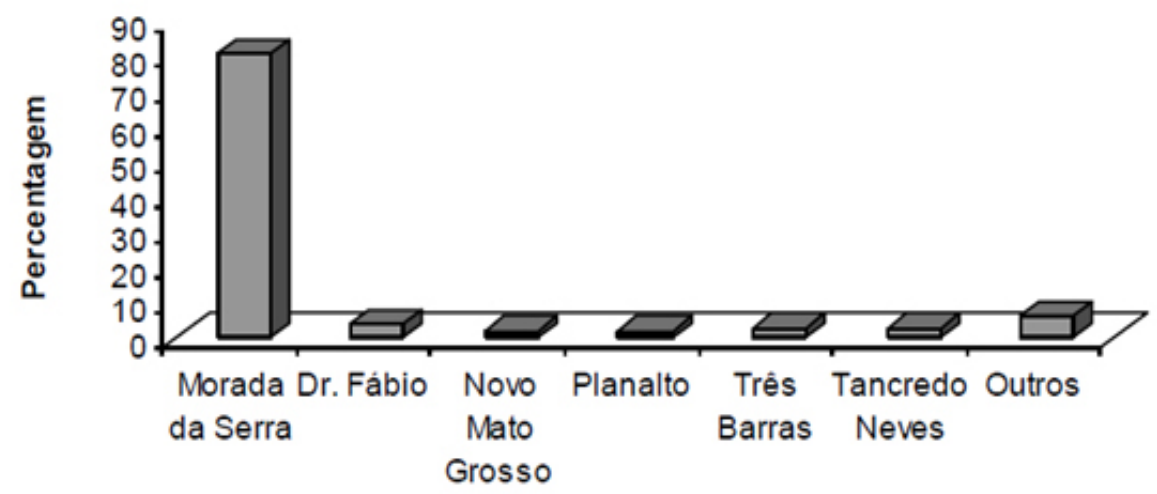

Bairro de Residência

Figura 2. Local de procedência dos entrevistados do Parque Municipal Lagoa Encantada, Cuiabá (MT). 2010.

Entre os 110 frequentadores entrevistados, existe uma maior proporção de visitantes do sexo feminino, $61,8 \%$, e $38,2 \%$ dos frequentadores do sexo masculino. Para Nascimento et al. (2013), a diferença entre os entrevistados foi de que 55\% dos entrevistados são do sexo masculino e $45 \%$ do sexo feminino.

A faixa etária dos frequentadores entrevistados do parque apresentou os seguintes resultados: 13,6\% deles se situam na faixa etária entre 10 a 20 anos; $20 \%$ na faixa etária entre 21 e 30 anos; 13,6\% entre 31 a 40 anos; 25,4\% entre 41 e 50 anos; 15,4\% entre 51 e 60 anos e 11,8\% para a faixa de mais de 60 anos. Já no trabalho realizado por Koga et al. (2011), em trilhas nos parques estaduais de São Paulo, a faixa etária entre 14 e 20 anos compôs 16,07\%; 21 e 30 anos, 34,34\%; 31 e 40 anos 23,50\%; e acima de 40 anos, 22,30\%.

Os dados obtidos indicam uma pequena diferença dos resultados adquiridos nos trabalhos realizados no Parque Mãe Bonifácia (PCMB) de Cuiabá, Mato Grosso (VILLANOVA, 2008), os quais apuraram que a maioria dos visitantes - 27\% - tinha entre 50 e 59 anos, 26\% entre 40 e 49 anos, 21\% entre 20 e 29 anos, 19\% entre 30 e 39 anos e 7\% com mais de 60 anos. E na Floresta Nacional (FLONA) de Ipanema, os jovens até 30 anos também são a maioria dos visitantes (SOUZA; MARTOS, 2008).

A grande maioria das pessoas que frequentam o parque são pessoas casadas $50,9 \%, 40 \%$ de solteiros/as, $7,3 \%$ são viúvo/as e 1,8\% divorciados/as. 
Com relação à renda familiar, foram consideradas cinco categorias, sendo $11,8 \%$ com renda mensal de $\mathrm{R} \$ 510,00 ; 41,8 \%$ dos entrevistados têm renda mensal entre $R \$ 510,00$ e $R \$ 1.530,00 ; 35,4 \%$ entre $R \$ 1.530,00$ e $R \$ 2.550,00,5,4 \%$ entre $\mathrm{R} \$ 2.550,00$ e $\mathrm{R} \$ 3.570,00$, e 5,4\% com renda superior a $\mathrm{R} \$ 3.570,00$. Diferente dos resultados encontrados por Malta e Costa (2009) que, em sua pesquisa no Parque Nacional da Tijuca, apontaram que 31,58\% dos entrevistados recebem acima de 10 salários mínimos, seguidos de 35,97\% recebendo até quatro salários, algo em torno de 2.400 reais.

Tabela 1. Nível de escolaridade dos entrevistados do Parque Municipal Lagoa Encantada, Cuiabá (MT), 2010

\begin{tabular}{lc}
\hline Grau de Escolaridade & $\mathbf{\%}$ \\
\hline Ensino Fundamental & 23,63 \\
Ensino Médio & 49,09 \\
Ensino Superior & 25,45 \\
Especialização & 1,8 \\
\hline
\end{tabular}

De acordo com os resultados (Tabela 1), considerando-se quatro categorias de educação formal, observou-se que 49,09\% dos entrevistados possuem ensino superior completo. Nos estudos realizados no Parque Estadual Mãe Bonifácia (MT), a maioria dos frequentadores possui nível superior, cerca de 73\% (NASCIMENTO et al., 2013). Em estudos realizados por Hildebrand et al. (2002), no Bosque Alemão em Curitiba, foram encontrados percentuais semelhantes, 43,2\% nível superior completo, 22,1\% superior incompleto, 29,5\% secundário e apenas 5,3 com o nível primário. 


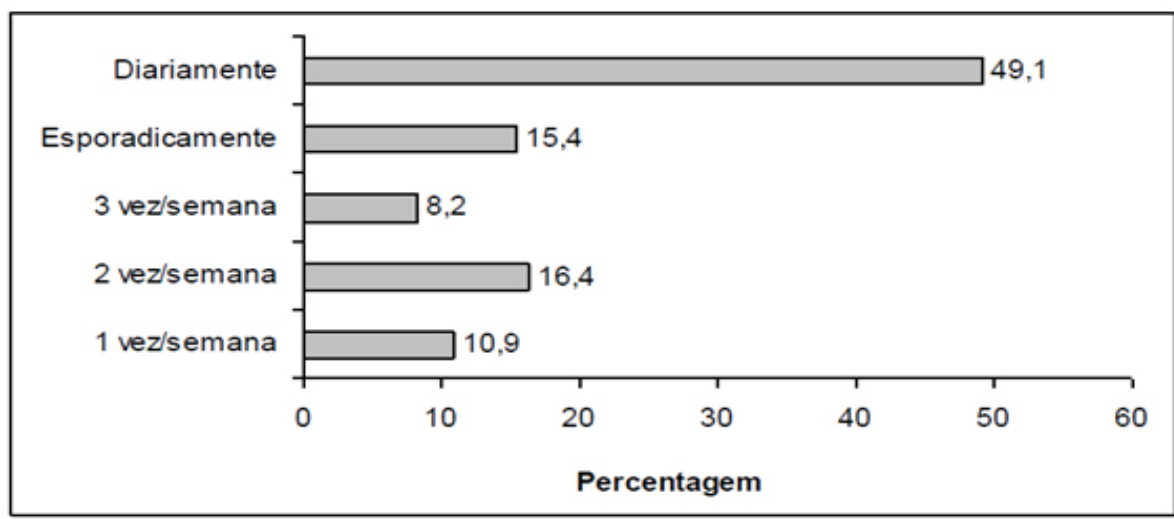

Figura 3. Frequência dos entrevistados do Parque Municipal Lagoa Encantada, Cuiabá (MT), 2010.

Pela Figura 3, pode-se observar que $49 \%$ dos entrevistados frequentam o parque diariamente, $16 \%$ duas vezes por semana, $15 \%$ frequentam esporadicamente, $11 \%$ uma vez por semana e apenas $8 \%$ dos entrevistados frequentam o parque três vezes por semana.

Quanto ao tempo de permanência por visita ao parque, 39\% dos entrevistados costumam permanecer até uma hora no parque, $44 \%$ de uma a duas horas, e $17 \%$ permanecem no parque por mais de duas horas.

Quanto ao período do dia de preferência em que os entrevistados frequentam o parque, $54 \%$ preferem o período matutino, $30 \%$ o vespertino e $16 \%$ frequentam o parque em ambos os períodos.

Com relação ao item segurança, $83 \%$ dos frequentadores entrevistados sentem-se seguros enquanto realizam atividades no parque e $17 \%$ não se sentem seguros. Quanto ao fato de que já souberam de ocorrência de assaltos no parque, $76 \%$ afirmaram que nunca souberam de assalto, enquanto que $24 \%$ dos entrevistados já souberam de ocorrência de assalto no parque.

Quanto à finalidade de utilização do parque pelos entrevistados, $56 \%$ fazem caminhadas, $7 \%$ frequentam para passear, $5 \%$ para trabalho e $32 \%$ em atividades mistas. 


\subsection{VALORIZAÇÃO DE CUSTO DE VIAGEM (MCV)}

Neste método foram observados quais os meios de transportes que as pessoas utilizam para o deslocamento até ao parque para que se possa calcular qual a disposição a pagar (DAP) para o entrevistado que se desloca até o parque. Considerando as 110 pessoas entrevistadas, 78\% foram caminhando, 15\% utilizaram o carro como meio de transporte para se deslocar até o parque, uma de ônibus, 5\% de motocicleta e $2 \%$ de bicicleta.

Os frequentadores entrevistados percorreram em média uma distância de 6,36 quilômetros por viagem de ida e volta, consumindo um total de 9,15 litros de combustível. O preço médio utilizado para o combustível é de $\mathrm{R} \$ 2,22 /$ litro, calculado baseando-se no preço atual dos combustíveis, com o álcool a $\mathrm{R} \$ 1,57$ /itro, gasolina a $\mathrm{R} \$ 2,87$ /litro e para os entrevistados que utilizaram ônibus calculou-se o valor da passagem no valor de $\mathrm{R} \$ 2,50$.

Para estimativa dos custos de deslocamento ida e volta por pessoa, referentes apenas ao gasto com combustível, ficando de fora gastos com pneus, depreciação do automóvel, foi feita uma média ponderada do número de pessoas transportadas por automóvel por viagem por lotação.

Tabela 3. Número de pessoas e estimativa do custo de deslocamento, Cuiabá (MT), 2010

\begin{tabular}{lcccccc}
\hline $\begin{array}{c}\text { Meio de } \\
\text { transporte }\end{array}$ & $\begin{array}{c}\text { Número de } \\
\text { pessoas }\end{array}$ & $\begin{array}{c}\text { Distância } \\
\text { ida e volta } \\
(\mathrm{Km})\end{array}$ & $\begin{array}{c}\text { custo } \\
\text { combustivel } \\
\text { (R\$/Litros) }\end{array}$ & $\begin{array}{c}\text { Consu- } \\
\text { mo de } \\
\text { combustivel } \\
\text { (Litros) }\end{array}$ & $\begin{array}{c}\text { Custo Total } \\
\text { de trans- } \\
\text { porte (R\$) }\end{array}$ & $\begin{array}{c}\text { Custo por } \\
\text { pessoa }\end{array}$ \\
\hline A pé & 86 & & & & & 0,00 \\
Onnibus & 1 & 1,6 & 2,50 & - & 5,00 & 5,00 \\
Carro - A & 9 & 53,20 & 1,57 & 4,9 & 7,69 & 0,85 \\
Carro - G & 8 & 22,70 & 2,85 & 1,74 & 4,96 & 0,62 \\
Moto - G & 6 & 75,20 & 2,85 & 2,51 & 7,15 & 1,19 \\
\hline \multicolumn{1}{c}{ Total } & 110 & 152,70 & & 9,15 & 24,80 & \\
\hline
\end{tabular}

Pela Tabela 3 observa-se que, entre os frequentadores entrevistados no parque, seis pessoas entrevistadas utilizaram moto a gasolina sem o carona como meio de transporte para se deslocar até o parque, para essas seis pessoas obteve-se uma estimativa de custo médio de $\mathrm{R} \$ 1,19 /$ pessoa/viagem de ida e volta. 
Entre os entrevistados no parque, uma única pessoa que utilizou o ônibus para deslocamento, esta pessoa utilizou-se da linha 311 (Novo Mato Grosso), gastando assim $\mathrm{R} \$ 5,00 /$ pessoa/viagem de ida e volta. De posse dos valores médios ponderados, em que seis pessoas se deslocam de motocicleta a um custo total de $R \$ 7,15$; 01 pessoa se desloca de ônibus a um custo de $\mathrm{R} \$ 5,00 ; 9$ pessoas em automóveis movido a álcool com lotação de uma pessoa a um custo total de $\mathrm{R} \$ 7,69 ; 8$ pessoas em automóveis movido a gasolina com lotação de uma pessoa a $\mathrm{R}$ \$ 4,96; obtém-se um custo total final de $\mathrm{R} \$ 24,80$.

Esse valor estimado dividido pelo número total de frequentadores entrevistados que se deslocaram por meios automotores (110) resulta em um valor médio ponderado de $R \$ 1,03$, ou seja, os valores obtidos pelo Método Custo de Viagem (MCV) mostram que os entrevistados do parque estão dispostos a desembolsar o equivalente a $\mathrm{R} \$ 1,03 /$ pessoa/visita. Esse resultado corrobora com os de Nascimento et al. (2013) que, em seu trabalho no Parque Estadual Mãe Bonifácia (MT), encontraram Dap (disposição a pagar) de $\mathrm{R} \$ 1,21 /$ pessoa/visita ao bosque para manutenção das áreas verdes.

O número estimado de pessoas que visitam o parque durante a semana por dia é de 1.568 pessoas/dia (segunda a domingo). Considerando que todos os dias do ano haverá movimento no parque, teremos 365 dias no ano, logo $(365 \mathrm{x}$ 1.568) 572.320 pessoas visitando o parque anualmente (segunda a domingo). Por-

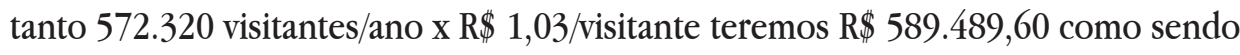
o valor do parque pelo MCV na melhor das hipóteses.

\subsection{VALORAÇÃO CONTINGENTE (MVC)}

Quando consultados sobre a disposição a pagar pela visita ao parque, $81 \%$ dos frequentadores entrevistados julgaram correta a cobrança pela visita, e 19\% são a favor da entrada franca.

Os resultados da pesquisa mostram que, no que diz respeito à disposição a pagar (DAP) pelo uso do PMLE por visita, 39\% dos entrevistados estão dispostos a pagar um valor entre $R \$ 0,50$ e $R \$ 1,00$ por entrada, $12 \%$ um valor entre $R \$ 1,00$ e $R \$ 3,00,11 \%$ entre $R \$ 3,00$ e $R \$ 5,00,19 \%$ pagariam mais de $R \$ 6,00$ e $19 \%$ não estariam dispostos a pagar nada pelo uso do parque. Já no trabalho realizado por Sousa e Mota (2006), no Parque Metropolitano de Pituaçu (PMP), em Salvador (BA), o método de avaliação contingente permitiu constatar que 63,4\% dos usuários do 
PMP estão dispostos a pagar pela manutenção das suas funções, com $R \$ 7,72 /$ mês, ou seja, 0,25733 centavos por dia.

Utilizando o valor $\mathrm{R} \$ 1,00$, que foi o maior obtido revelado pela maioria dos entrevistados (34\%) quanto à sua disposição a pagar (DAP) para entrar no parque para estimativa do valor anual do parque, teremos: para 572.320 pessoas $(365 \mathrm{x}$ 1568) visitando o parque anualmente (segunda a domingo), um total estimado de $\mathrm{R} \$ 572.320,00$ ( $\mathrm{R} \$ 1,00$ × 572.320 pessoas) como o valor do parque pelo Método de Valoração Contingente na melhor das hipóteses.

\section{CONSIDERAÇÕES FINAIS}

Os valores obtidos pelo Método Custo de Viagem mostram que os frequentadores entrevistados no parque têm uma disposição para desembolsar o equivalente a $\mathrm{R} \$ 1,03 /$ pessoa/visita ao parque.

A disposição média a pagar encontrada para o público entrevistado pelo Método de Valoração Contingente foi de um valor que se situa entre $R \$ 0,50$ e $R \$$ 1,00 por pessoa/visita ao parque.

Os moradores da região do parque, como a morada da serra, foram os mais beneficiados pelos serviços ambientais oferecidos pela criação do Parque Estadual Lagoa Encantada.

O parque atende todas as faixas etárias, característica que demonstra acerto na estrutura e funcionamento no atendimento ao público de ambos os sexos.

A maioria dos frequentadores é maior de idade, casados, com renda mensal familiar entre $R \$ 510,00$ e $R \$ 1.530,00$, com ensino médio. Eles visitam o parque diariamente para fazer caminhada, sentem-se seguros na área do parque, permanecendo de uma a duas horas no período matutino.

\section{REFERÊNCIAS}

ABREU, E. A. de; SILVA, A. G. da; SILVA JUNIOR, G. G. da; MELO, R. S. N. de. Uma análise do custo de viagem para a praia da avenida em Maceió. In: XIVI CONGRESSO DA SOCIEDADE BRASILEIRA DE ECONOMIA, ADMINISTRAÇÃO E SOCIEDADE RURAL, 2008, Rio Branco. Anais... Rio Branco: Sociedade Brasileira de Economia, Administração e Sociedade Rural, 2008. 
CUNHA-MENEZES, P. Raising the priority of urban areas in protected area systems in Brazil and beyond. In: TZYNA, T. The Urban Imperative: Urban Outreach Strategies for Protect areas Agencies. Sacramento: California Institute of Public Affairs. 2005. Disponível em: < http://www.interenvironment.org/pa/menezes.htm $>$. Acesso em: 04 mar. 2011.

FERREIRA, A. C. S. Contabilidade Ambiental. São Paulo: Atlas, 2003.

HILDEBRAND, Elisabeth; GRAÇA, Luiz Roberto; HOEFLICH, Vitor Afonso. "Valoração contingente" na avaliação econômica de áreas verdes urbanas. Revista Floresta, Curitiba, 32 (1): p. 121-132. 2002.

KOGA, Érika Sayuri; OLIVEIRA, Anna Carolina Lobo de; OLIVEIRA, Caroline da Silva. Perfil dos visitantes nos parques estaduais de São Paulo: estudo do Programa Trilhas de São Paulo. In: CONGRESSO NACIONAL DE ECOTURISMO; ENCONTRO INTERDISCIPLINAR DE ECOTURISMO EM UNIDADES DE CONSERVAÇÃO, v. 4, n. 4, 2011, São Paulo. Anais... São Paulo: Revista Brasileira de Ecoturismo, 2011. p. 554.

MAY, Tim. Pesquisa social: questões, métodos e processos. Trad. de C. A. S. N. Soares. 3. ed. Porto Alegre: Artmed, 2004.

MEDEIROS, Rodrigo; YOUNG, Carlos Eduardo Frickmann. Contribuição das unidades de conservação brasileiras para a economia nacional: Relatório Final. Brasília: UNEP-WCMC, 2011.

MOTTA, Ronaldo Seroa da. Manual para Valoração Econômica de Recursos Ambientais. Rio de Janeiro: IPEA/MMA/PNUD/CNPq, 1997.

NASCIMENTO, Stéphanie Thayssa Mattos Fontes; RIBEIRO, Edilene Silva; SOUSA, Roberto Antônio Ticle de Melo e. Valoração econômica de uma unidade de conservação urbana, Cuiabá, Mato Grosso. Revista Interações, Campo Grande, v. 14, n. 1, p. $79-88$, jan./jun. 2013.

NOGUEIRA, J. M.; MEDEIROS, M. A. A.; ARRUDA, F. S. T. Valoração Econômica do Meio Ambiente: ciência ou empiricismo? Caderno de Pesquisas em Desenvolvimento Agrícola e Meio Ambiente. Brasília. v. 17, n. 2, p. 81-115, 2000. Disponível em: http://www.unb.br/face/eco/nepama2k/NEPAMA002.doc. Acesso em: 09 out. 2010 . 
SALLES, D. J. P. C. Constitucionalismo ambiental, paradoxo e crise ante as incertezas e os riscos gerados pelo desenvolvimento tecnológico. Revista Âmbito Jurídico - no 81 - Ano XIII. ISSN: 1518-0360. 2010. Disponível em: http://www.âmbitojuridico.com.br/site/índex.php?n_link=revista_artigos_leitura\&artigo_id=8410. Acesso em: 16 maio 2011.

SOUSA, Geneci Braz de; MOTA, José Aroudo. Valoração econômica de áreas de recreação: o caso do parque metropolitano de Pituaçu, Salvador, BA. Revista de Economia, Curitiba, v. 32, n. 1 (ano 30), p. 37-55, jan./jun. 2006.

SOUZA, Paula Cristina de; MARTOS, Henry Lesjak. Estudo do uso público e análise ambiental das trilhas em uma unidade de conservação de uso sustentável: floresta nacional de Ipanema, Iperó-SP. Revista Árvore, Viçosa, MG, v. 32, n. 1, p. 91-100, 2008.

TAKAHASHI, L. Y.; MARTINS, S. S. O perfil dos visitantes de um Parque Municipal situado no perímetro urbano. In: ENCONTRO NACIONAL SOBRE ARBORIZAÇÃO URBANA. Anais... Curitiba: UFPR/FUPEF, 1990. p. 197-210.

TOGNELLA, M. M. P. Valoração econômica: estudo de caso para o ecossistema manguezal - Bertioga e Cananéia. 1995. 161f. Dissertação (Mestrado em Oceanografia) - Universidade de São Paulo, São Paulo, 1995.

VILLANOVA, Silvia Regina Fernandes. Composição florística e valoração econômica de uma unidade de conservação urbana. 2008. 98f. Dissertação (Mestrado em Ciências Florestais e Ambientais) - Universidade Federal de Mato Grosso. Cuiabá, 2008.

Recebido em: 04/10/2014 Aceito em: 13/07/2017 